\title{
Knowledge Management and Culture: A Misunderstood Paradox
}

\begin{abstract}
How can one make sense of, and assess the relationship between two phenomena that are difficult to define, subjective, highly contextual by nature, mostly invisible, and ambiguous? Facing a similar challenge, this paper is an attempt to explore the impact of organisational culture on knowledge management (KM) policies, procedures and practices in organisations, acknowledged as important in most contemporary KM literature. This paper is based on an empirical study of the KM practices of 13 global firms. The study with a strategic focus probed many issues including culture. The findings demonstrate that organisations, aware of the possible impact of culture on $\mathrm{KM}$, take a simplistic either/or approach to it. They regard their culture either as appropriate and a viable starting point for KM, or use KM as part of a culture change programme. We argue that the relationship between $\mathrm{KM}$ and culture is much more complex, and culture not only provides a context knowledge sharing but conceptually overlaps with social tacit knowledge, and inseparable both evolve perpetually.
\end{abstract}

\section{Milieu of the research}

This research started as a comprehensive study of how global firms were making sense of, and adopting the notion of knowledge management (KM), which has become one of the latest buzzwords in management. The knowledge managers of 13 global firms operating in different industries were interviewed. The study has a strategic focus and explored many issues including the impact of organisational culture on $\mathrm{KM}$ as perceived by the top knowledge managers, who all but two had been involved in the inception, design and implementation of the KM policies and practices in their organisations. In the KM literature, culture has been identified as one of the main factors impacting the success or otherwise of $\mathrm{KM}$ practices in organisations. The findings demonstrate that practitioners presume the relationship between culture and $\mathrm{KM}$ as rather simple and unidirectional, in line with most messages from the literature; either culture was assumed to be appropriate for KM to be based on, or KM was used as a tool for culture change if it had been deemed unsuitable; both approaches implicitly assume that managers can change culture although the former saw no need to do so. We argue that the relationship between culture and $\mathrm{KM}$ is much more complex and social tacit knowledge and culture are two overlapping concepts. Culture influences $\mathrm{KM}$, as values impact behaviour, and through its practice KM is bound to impact culture, which in turn affects how people create, share, and use knowledge in organisations both implicitly and explicitly. Therefore, both are inseparable and evolve perpetually. 


\section{Organisational Culture: Conceptually Ambiguous}

Most studies on culture are concerned with issues at societal level and originate from anthropology. Hofstede et al (1990) argue that the concept of organisational culture was first introduced to management literature by Blake and Norton (1964) describing what was till then known as 'climate'. But Jaques's (1952: 251) description of “the culture of the factory" as a shared way of thinking and doing things predates that. The interest in the subject took off later (e.g. Deal \& Kennedy, 1982; Louis, 1983; Peters \& Waterman, 1982; Pettigrew, 1979; Siehl \& Martin, 1984; Silverweig \& Allen, 1976; Trice \& Beyer, 1993; Van Maanen, 1988). The organisational culture literature also draws from anthropology (e.g. Alvesson, 1993; Martin, 1992; Smircich, 1983) and implicitly treats organisations and societies as similar, although there are many discernable differences between them. Organisations are intentionally structured, with pre-set purposes, have different characteristics from societies in how they form and evolve (Heracelous, 1996), and unlike societies embrace only a part of individuals' lives (Hendry, 1999). On the other hand, organisational culture is embedded in the culture of the society in which it operates (Hofstede, 1980). Hence, it is argued that "any attempt to apply anthropologically-driven theories to contemporary organisations must be conducted with extreme caution", although it should not be ruled out entirely (Hendry, 1999: 557).

Hatch (1997: 202) argues that culture is "probably the most difficult of all organisational concepts to define", and a consensus on its definition has not been reached yet (ibid.). Most debates share some basic assumptions that: organisational culture is holistic, historically determined, related to anthropological concepts, socially constructed, soft, and difficult to change (Hofstede et al, 1990). It is been demonstrated that organisations usually have a contingent of subcultures formed around the type of work people do (Deal \& Kennedy, 1982; Handy, 1986; Harrison, 1972; Schein, 1996), because of interpersonal attraction (similar personalities are attracted to a job or a position) and group cohesion through regular interactions (Van Maanen \& Barley, 1984). Therefore organisation culture is an approximate model (Newman \& Chaharbaghi, 1998). Subcultures have been classified based on whether they support, contradict, or simply exist alongside the overall culture (Siehl \& Martin, 1984). Culture is historically determined as it is based on shared experiences unique 
to the organisation and exists at different levels in terms of its visibility/embeddedness (Schein, 1996).

\section{Manageability of Culture}

On this issue the literature is divided. A growing number of debates on change management (e.g. Kilmann et al, 1986; Ouchi, 1980; Peters \& Waterman, 1982; Wilkins and Ouchi, 1983) have treated culture as a variable (Mumby, 1988), and a management tool (Hatch, 1997), based on the assumption that by influencing the social psychological, cultural and belief systems of an organisation managers can make them desirable (Stacey, 2000). The debate that culture can be managed is a modernist concern (Hatch, 1997). The dual role of culture both as an enabler and constraining (Peters \& Waterman, 1982) mirrors the freedom and control divide (Hendry, 1999), but it is argued that culture's role as a control mechanism has become more popular (Hope \& Hendry, 1995; Pascale, 1985; Posner, et al, 1985; Weick, 1987; Willmott, 1993). Advocates of this school of thought promote change and culture management. This implies that managers have the ability to modify or even radically change culture, hence this approach's popularity with practitioners (and of course with consultancy firms). It provides solace for managers by giving the impression that they can control even the most ambiguous aspects of their organisations. The rational is that behaviour, through values and norms is influenced by culture, therefore in order to make behaviour desirable managers (a top-down approach) try to impact it by influencing norms and values (Hatch, 1997). Many models, such as the 7S model (Peters \& Waterman, 1982) and the cultural web (Johnson \& Scholes, 1999) have been introduced to assist managers and researchers. The "unexamined" assumption is that managers are enormously visible with the power structure in their favour, although it is recognised that the intentions of top managers could be misunderstood or even ignored (Hatch, 1997).

Advocates of the opposite view argue that norms and values are deeply embedded in beliefs and assumptions, and because of its embeddedness culture is resistant to change (Hendry, 1999), which makes the notion of managing culture impossible (Hatch, 1997), hence the presumption that managers can change their organisational culture in a similar vein to other aspects of an organisation (e.g. structure) is illusive (Newman \& Chaharbaghi, 1998). This postmodernist approach also raises ethical 
concerns (Woodall, 1996), and highlights the benefits of relinquishing control such as better motivation and creativity (Hatch, 1997).

Hatch (1997) offers a third way, a "middle ground", the "symbolic interpretive" approach to organisational culture and argues that managers have the potential to become power symbols (Pfeffer, 1980). And they are part of the culture (managed by it), but at the same time try to manage it as well. The main message of the symbolic interpretive is that managers should try to understand culture's impact and role rather than regarding it as an entity hence, instead of trying to manage culture through change management programmes, managers should be aware of the cultural context for organisational change, as change programmes might produce unpredictable or even undesirable outcomes. Hatch (1997:235) elaborates,

Think of culture as a context for meaning making and interpretation. Do not think of trying to manage culture. Other people's meanings and interpretations are highly unmanageable. Think instead about trying to culturally manage your organisation, that is, manage your organisation with cultural awareness of the multiplicity of meanings that will be made of you and your efforts

Despite its ambiguity, at face value, Hatch's normative solution of bringing together some positive elements of two rather incomplete, abstract, and simplistic approaches seems logical. But she advocates what she is warning against. The managers are singled-out (a top-down approach again) for their unique understanding of culture and the future "multiplicity of meanings" made by others in the organisation in response to their efforts, implying in contradiction to what she says about future unpredictability, managers can foresee a range of internal reactions. Therefore, she assumes that future unpredictability applies only to external factors. Hatch does not take into account the paradoxical nature of organisations or explores the implications of her approach. Therefore, despite its normative nature, her solution provides little insight for practitioners other than advising them to be culturally aware of the "multiplicity of meanings", whatever that might be.

The research on organisational culture has been categorised into three complementary perspectives: integration, differentiation, and fragmentation (Meyerson \& Martin, 
1987; Martin \& Meyerson, 1988). The first perspective refers to a highly consensual view of the culture (e.g. Ouchi, 1981; O’Reilly et al, 1991; Schein, 1985, 1996, 1999), aiming for the predictability of behaviour, which paradoxically might not lead to innovation and creativity (Newell et al, 2002). Using dichotomous or oppositional thinking, differentiation perspective assumes that inconsistent interpretations are present at the higher level of culture, but consensus exists in subcultures (e.g. Alvesson, 1993, Barley, 1986; Bell, 1990; Martin et al, 1985; Mumby, 1987; 1988; Rosen, 1985; Rousseau, 1990b; Young, 1991). Fragmentation, a post-modernist critique of the differentiation perspective (Martin, 1992), regards culture as neither consistent nor stable, and full of contrasting and paradoxical issues (e.g., Schultz, 1992; Wels, 1996), offering multiplicity. Ambiguity, viewed inevitable, and unproblematic, exists in culture (e.g. Brown \& Duguid, 1991; Cohen et al, 1972; Daft \& Weick, 1984; Gherardi, 1995; Hatch, 1999, Meyerson, 1991a, 1991b, 1994; Starbuck, 1983; Weick, 1991). In this perspective culture is analogically, a series of shades of grey as opposed to the black and white picture depicted by differentiation, or the single colour of integration perspective (Martin, 2002). A framework has been put forward to bring the three perspectives together (ibid.), consisting of the shared aspects of culture (integration), its facets that are interpreted differently (differentiation), and the irreconcilable aspects of culture (fragmentation).

\section{Knowledge Management}

Knowledge management, one of the latest concepts in management which has become popular with bigger organisations, has been defined in many ways, for example Tsoukas and Vladimirou (2001:990) say,

Knowledge management ....is primarily the dynamic process of turning an unreflected practice into a reflective one by elucidating the rules guiding the activities of the practice, by helping give a particular shape to collective understandings, and by facilitating the emergence of heuristic knowledge.

In this study knowledge management is described as a conscious, reflective and systematic approach to the enhancement, and development of knowledge creation, sharing and dissemination in organisations. Most debates in KM literature have expanded Polanyi's (1966) categorisation of knowledge as tacit and explicit, which he 
puts only at individual level, by arguing that knowledge, through socialisation also exists at group and organisational level (social knowledge). Social tacit knowledge is the focus of most KM debates (Spender, 1996).

\section{Culture and Social Tacit Knowledge}

The review of organisational culture and knowledge management literature highlights the entangled and overlapping nature of culture and social tacit knowledge. John Van Maanen's (1988: 3) definition of culture provides a fine example:

Culture refers to the knowledge members of a given group are thought to more or less share; knowledge of the sort that is said to inform, embed, shape, and account for the routine and not-so-routine activities of the members of the culture.

This definition highlights the culturally embedded processes of knowledge creation, use, and transfer, and implicitly equates social tacit knowledge with culture. Other examples also underline this entanglement. Echoing the other side of Van Maanen's definition, Hodgson (1999: 200) says that organisational knowledge is "contextdependent, culture-bound and institutionalised". Connor \& Prahalad (2002: 81) add a third category to the tacit-explicit divide, that of cultural knowledge, which they argue is "in the assumptions, and beliefs used by members to assign value and significance to new information or knowledge". And Blackler's (1995) review of organisational learning literature reveals five kinds of knowledge, one he labels "encultured knowledge", relating to the process of shared understandings dependent on language and socialisation.

In the KM literature, knowledge has been defined either as an entity or as an event (Newell et al, 2001; Styhre, 2003), the former being influenced by cognitive psychology, based on Polanyi's tacit/explicit divide, where ontologically, knowledge exists at individual (created in social interactions), group, and organisational level (e.g. Brown \& Duguid, 1991; Nonaka, 1991, 1994; Weick, 1991). Knowledge as an event (a process) is created through social processes (Styhre, 2003), hence it is not a "thing" and some even argue that ontologically, no divide exists between individual and social level (see Stacey, 2001). It is clear that when knowledge is assumed to be 
an entity, then in KM, culture (its context) could be considered as a managerial tool. This approach provides a distinction between knowledge and culture. If however, knowledge is assumed as an event (a process), then it is inseparable from, and intertwined with culture, which makes the approach of changing culture rather nonsensical, as one cannot change one without changing the other.

Social psychologist, Edgar Schein, one of the influential advocates of culture management school perspective has combined aspects of his work on culture (1985, 1991a, 1991b) with organizational learning debate (Schein, 1996). He says culture is the root for organisations' failure "to learn to how learn", and manifests itself at three levels: deep tacit assumptions (its essence), espoused values (what the group ideally wishes to be and present itself as), and day-to-day behaviour (a complex compromise between the deeper assumptions, espoused values and the immediate needs of the situation). He identifies three different cultures in organisations: operator culture, engineering culture, and executive culture; the operator culture develops through human interactions. The engineers prefer pragmatic people-free solutions, based on linear, simple cause and effect quantitative thinking. The third category has a financial focus, and as organisations grow they become "depersonalised and abstract and, therefore, have to be run by rules, routines (systems), and rituals" (p, 15), and by implication, all top-down approaches regard humans as a resource like any other. Schein says organisations do not learn effectively unless these occupational cultures and their implications have been addressed. He says the alignment between these cultures could be disturbed when organisations "learn in a generative way, when they attempt to reinvent themselves because technologies and environmental conditions have changed drastically" ( $p, 16)$, hence the necessity of cross-cultural dialogue for creating common understanding (integration) in complex organisations, which unlike the ones in the fragmentation perspective (Meyerson \& Martin, 1987; Martin \& Meyerson, 1988; Martin, 2002) don't face paradoxes and problems are solved not managed. But how does this fit in with the messages that urge organisations to be innovative? It seems that breaking the mould and harmony do not go hand in hand.

Martin (2002) says that Schein's work belongs to the integration camp. However his subcultures more resonate with the differentiation camp; only the normative aspect of his message, uncomfortable with tension existing among subcultures, strives for an 
integrated culture. Many questions are not addressed by Schein. For example, it is not clear how the culture change takes place and whether people, after moving to another sphere of the organisation, could identify with their preceding culture. Does the new culture automatically overrides the previous one, or if one could get stuck in a certain kind of culture even if she has moved up on the organisational ladder. Schein's debate creates an interesting dilemma, a contradiction to most KM debates which regard the human factor as integral in KM and usually advocate a top-down approach as well. Schein suggests that executive culture views humans as means to an end, a resource like any other, which undermines the importance attached to it by KM.

The role of culture has also been explored on, for example, knowledge creation in communities of practice (Lave \& Wenger, 1991; Brown \& Duguid, 1991), the importance of creating a knowledge sharing culture (Banks, 1999; Lubit, 2001), cultural barriers to knowledge creation and utilisation (Lang, 2001; De Long \& Fahey, 2000), cultural embeddedness of some knowledge creating models (Glisby \& Holden, 2003), exploring the relationship between culture and KM (De Long \& Fahey, 2000; Mc Dermott \& O'Dell, 2001), using concepts from organisational culture literature. Not surprisingly, two main approaches could be identified: either culture is assumed as appropriate for $\mathrm{KM}$ or needs to change using $\mathrm{KM}$ as a tool.

\section{Culture Change and KM}

Culture has been recognised as a barrier in the KM literature (e.g. Banks, 1999; De Long \& Fahey, 2000; Lang, 2001; Lubit, 2001), with different approaches to combat it. Lang (2001) suggests experimenting with new organisational forms and reward systems to create a more receptive culture to KM. De Long and Fahey (2000) argue culture creates the context for social interactions and assumptions about knowledge, its relevance and significance are also culture based. Lubit (2001) describes how a culture which inhibits use of knowledge developed elsewhere (not-invented here syndrome), hinders dissemination of knowledge e.g. best practice, and recommends the following steps for developing a knowledge sharing culture: mentoring, discussion groups, staff working in different parts of the organisation, outward looking approach, and tolerance of mistakes. 


\section{Working with Culture}

Following Schein, Mc Dermott and O'Dell (2001) identify three kinds of cultures in organisations, visible, embedded and invisible (core values). They studied five companies identified in the literature as being effective at knowledge sharing. McDermott and O'Dell argue that if culture is the biggest barrier to KM then why not match KM to culture, therefore, the normative part of their debate fits better with Hatch's (1997) symbolic interpretive approach, moving from a modernist base (mainly integration/ differentiation) to a post-modernist recipe with recommendations to match culture and knowledge sharing. By building on a core value, they argue, companies (through top management) can create a culture that supports knowledge sharing. This is based on the assumption that the core value (which might be made explicit) does not inhibit knowledge sharing. But they concede that identifying organisational values which can provide a catalyst for sharing knowledge is difficult. So with a slight departure from Schein's debate, they conclude that design and application of KM has more to do with negating the impact of cultural barriers to sharing knowledge than changing the culture. But their recommendations impact culture anyway. Their research is biased because the companies they chose to study had all been picked because they were good at knowledge sharing and creation even before adopting KM. The research would have yielded different results if another set of organisations had been picked. While one tends to agree with the logical reasoning of their debate, it is clear that McDermott and O'Dell's argument cannot provide insight for the organisations that management perceive lack the "knowledge sharing culture". And there is no clue or not a set of criteria to identify the characteristics of a "knowledge sharing culture" in their debate, other than being successful. Are they assuming that this is a unique culture to all efficient and successful organisations? It is easy to handpick a small sample of organisations credited with the best practice in the KM literature and come to the conclusion that matching KM to the company culture is the best practical solution.

\section{The Findings}

Most knowledge managers had been with their company for a long time, and involved in the design and implementation of their KM policies and practices from the start. They described their company's culture differently using words such as entrepreneurial, innovative, dynamic, frenetic, chaotic, anti-bureaucratic, risk-averse, 
open, informal, collegiate, meritocracy-based, flexible, supportive, friendly, positive, and even caring. These global companies, with a dispersed geographical presence around the world shared some problems. One was the clash of local and corporate culture one manager $(\mathrm{G})$ explained,

A defined culture gets less clear, so there is inevitably more fuzziness, if you like, in the culture. There is increasingly a recognition that we do not want to lose the local culture but we do want to have some consistency.

These subcultures were formed not around the type of jobs people did (that was also present), but local societies' culture were making a difference. The management tried to harmonise the overall culture, at the same time conscious that they couldn't (or perhaps didn't want to) change the local culture. It was in effect treated as managing a paradox.

Overall companies belonged to two camps: either they regarded their culture as appropriate for $\mathrm{KM}$, or felt they needed a culture change programme using $\mathrm{KM}$ among other tools. In five firms culture change was an ongoing planned project. Ironically, this assumption was also present in the rest of them. They did not have an explicit culture change programme not because they felt unable to, but they had deemed their culture as appropriate and a good starting point for their.

One firm, basing KM on its culture, had grown rapidly through acquisition, but the manager (B) could still identify a dominant culture and described it as, "strongly entrepreneurial; there are people here who, before their company was acquired, were running their own company. They had their own board and it was their world. And there are still strong traces of that in the organisational culture here. Standardisation, centralisation are not natural things here for a lot of people. They are used to be able to operate independently and just to get on with pursuing business. So that is a large part of the culture". To us that seemed more chaotic than entrepreneurial, and when we probed how would that culture impact knowledge sharing, as they seemed incompatible? Acknowledging the challenge, he said their KM approach was to try to link parts of the structure not linked formally (assuming knowledge sharing, and creation already takes place through the formal structure). Effectively, this was a 
gradual culture change programme although it had not been thought of, or labelled, as one. This pattern of managerial thinking was prevalent; most initiatives were considered by looking at a limited number of variables and in most cases ignoring their implications. It is clear that an entrepreneurial culture, a phenomena advocated in KM literature (Lang, 2001) also has a negative side potentially damaging or unhelpful to KM, as groups may become reluctant to share knowledge. However the manager believed that, with regard to KM, the company considered its culture strong and embraced it rather than trying to change it. In other words, they strived to work with the culture rather than artificially changing it, which seemed a rather anomalous strategy of integrating the company, as on the surface at least, it would go against that goal by reinforcing the unsynchronised parts of the culture. And as far as they were concerned KM was broadly used to facilitate integration by bypassing organisational structure and creating channels and possibilities for communications in parts of the company where otherwise they would not have taken place, as the manager (B) put it, in some ways to provide "an effective infrastructure". Overtime this kind of knowledge sharing, and creation would impact the culture, which in turn would impact the KM procedures, creating a perpetual cycle, resulting in the co-evolution of both organisational culture and KM. It is worth noting that the interplay between culture and structure was evident in most companies, and structure was assumed to provide a more practical tool with less unpredictable outcomes to experiment with.

Another manager (C), rather enthusiastically, described his company's culture as being "innovative, creative, it's as anti-bureaucratic as you can possibly imagine. It's chaotic, it's anarchic and the result is fantastic". He felt the company had always been good at knowledge sharing as, for example, 3 decades ago it had manually set up one of the first "experts' directories" in the industry where employees' expertise registered in the head office with a person in charge of updating and disseminating it. This is made easier by technology today where a computerised version of the "experts' yellow pages", is one of the most popular IT enablers in the KM industry. Their approach to KM, embedded in their culture, was ensuring that more face-to-face interactions took place among employees, especially the ones who had common expertise but were dispersed around the world. This firm could have been neatly included in McDermott \& O'Dell's study without changing the outcomes. 
Another company (D), privatised in the 1990s, had gone through a phase of major restructuring which the current management felt, had created enormous gaps in the company, and the emerging culture, had been deemed undesirable anyway, hence introducing a culture change programme to make the first one work. The manager (D) who had worked in other blue chip companies said the nature of business made this company the most complex he had worked for, although admitting that sometimes, they (the management) made things more complicated; an interesting observation by one of the management team. In effect, the company was a network of diverse business units belonging to different industries with different dynamics, impetus, and driving factors which explains his assessment of the complexity of the company, in short a myriad of clashing subcultures. In his view, the most important challenge facing the company was to manage the dichotomy (not the paradox) between what he termed "the guardianship and commerciality", that to some extent, reflected what he meant by the complex nature of the company's business. Interestingly, and perhaps to validate what he had said before, it seemed that the management were overcomplicating the matter as $\mathrm{KM}$ and extensive staff development initiatives were being introduced in conjunction with the leadership and change programmes, expecting the company to change comprehensively and systemically and at a dramatic speed. The company was in upheaval, and it was hard to make sense of the culture which was taking the full force of the imposed change.

The underlying assumption of this approach fits in with the strategic choice theory and systems thinking, where managers assume that their interventions could yield desired outcomes. If culture is identified as inadequate or inappropriate, like any other aspect of managing an organisation such as finance, it could be modified or even completely changed according to their intentions. It appears that they consider the organisational culture as a blank canvass on which they could paint a more desirable picture, ignoring the fact that it would be similar to an attempt to paint a new picture over an existing painting, which any amateur painter can testify is an impossible task.

An important issue highlighted by this research was the extent to which the nature of business affected the culture of an organisation. In one case (F), the industry dynamics were so fast moving and firms operating in it had to be very innovative and flexible. Hence the culture was used to rapid pace of change and the employees had to 
constantly acquire new skills and knowledge essential for the launch of new products. The manager (F) described knowledge as having a short life-span and his job as relentlessly delivering programmes to relentlessly update the skills and knowledge of the employees. We do not wish to overemphasise the role of industry similar to some attempts in strategic management literature (see for example, Porter, 1980), however, it seems plausible to argue that industry dynamics could impact the culture of organisations to some extent, but cannot explain the cultural differences between organisations operating in the same industry. Other context-specific factors such as history, strategy, and management practices make the difference.

\section{Conclusions}

From the findings, it could be argued that in some cases the paradox of stability $\mathrm{v}$ change was present but hardly acknowledged as such, even though in practice it was somehow being managed. All managers, who believed that culture could be manipulated and/or changed, perceived the relationship between culture and $\mathrm{KM}$ as a dilemma, hence their approach was either to try to change it or work with it. This oversimplification (see Miller, 1993 for its perils) meant that managers treat the existing culture as a blank canvass on which they could start a more desirable picture. Realistically however, the painter's skills would not make much of a difference here.

It could be argued that the issue could be better explained as a paradox. If culture is perceived as inappropriate, and managers try to change it with the aid of $\mathrm{KM}$, then practicing KM will impact the culture. If managers felt confident about the appropriateness of the culture, as was the case with five companies in this study, practicing KM overtime would change that culture any way. Conceptually, if social knowledge is assumed as an event then it would be difficult to separate it from culture, which makes the notion of changing culture in order to implement KM rather irrational.

To summarise, it is a perpetual process of change in which KM and culture both evolve and impact each other, regardless of culture being considered suitable or not. In both cases culture changes whether it is by design or unintentional. Therefore, it is like initiating radical change or incremental change even if you ignore the subcultures 
and disregard some of the debates on the impossibility of moulding culture in very complex social groupings such as global firms. 